\title{
Infrastructure Time: Long-term Matters in Collaborative Development
}

\author{
Helena Karasti ${ }^{1}$, Karen S. Baker ${ }^{2}$ \& Florence Millerand ${ }^{3}$ \\ ${ }^{1}$ Department of Information Processing Science, University of Oulu, P.O. Box 3000 FIN-90014 \\ Oulu, Finland (Phone: +358-8-5531913; Fax:+358-8-5531890; E-mail: helena.karasti@oulu.fi); \\ ${ }^{2}$ Scripps Institution of Oceanography, University of California at San Diego (UCSD), La Jolla, CA, \\ USA (E-mail: kbaker@ucsd.edu); ${ }^{3}$ Department of Social and Public Communication, University of \\ Quebec at Montreal (UQAM), Montreal, QC, Canada (E-mail: millerand.florence@uqam.ca)
}

\begin{abstract}
This paper addresses the collaborative development of information infrastructure for supporting data-rich scientific collaboration. Studying infrastructure development empirically not only in terms of spatial issues but also, and equally importantly, temporal ones, we illustrate how the long-term matters. Our case is about the collaborative development of a metadata standard for an ecological research domain. It is a complex example where standards are recognized as one element of infrastructure and standard-making efforts include integration of semantic work and software tools development. With a focus on the temporal scales of short-term and long-term, we analyze the practices and views of the main parties involved in the development of the standard. Our contributions are three-fold: 1) extension of the notion of infrastructure to more explicitly include the temporal dimension; 2) identification of two distinct temporal orientations in information infrastructure development work, namely 'project time' and 'infrastructure time', and 3) association of related development orientations, particularly 'continuing design' as a development orientation that recognizes 'infrastructure time'. We conclude by highlighting the need to enrich understandings of temporality in $\mathrm{CSCW}$, particularly towards longer time scales and more diversified temporal hybrids in collaborative infrastructure development. This work draws attention to the manifold ramifications that 'infrastructure time', as an example of more extended temporal scales, suggests for CSCW and e-Research infrastructures.
\end{abstract}

Key words: Collaborative information infrastructure development, Continuing design, Cyberinfrastructure, e-Infrastructure, e-Research, e-Science, Development orientation, Long-Term Ecological Research, Metadata standard, Standard-making, Temporal orientation, Temporal scale, Time research

\section{Introduction}

Recent innovations in technological support for scientific collaboration offer the potential for revolutionary changes in the ways research is undertaken (Atkins et al. 2003) and scientific information infrastructures have become of key significance to research communities interested in supporting a variety of broader scale initiatives (Bowker et al. forthcoming). Scientific collaborations using cyberinfrastructure - or e-Science, e-Research and e-Infrastructure as the emerg- 
ing field is also called ${ }^{1}$ - are currently astir with exciting developments: initial understandings exist about recent undertakings and new challenges abound for all stakeholders including funding agency managers, technology developers, domain scientists and data specialists. Tensions have been observed, however, between the promises and drive to create new ways of doing science and the experiences of those who attempt to render the visions feasible in the context of their scientific work (Jirotka et al. 2006; Vann and Bowker 2006).

Despite the technological underpinnings of e-Science, a number of studies and 'lessons learned' types of papers have revealed the importance of associated human/ social dimensions (e.g. Jirotka et al. 2005; Lawrence 2006; Spencer et al. 2006; Lee et al. 2006; Borgman et al. 2007). We continue this line of reasoning by investigating the intricacies involved in the collaborative development of scientific information infrastructures with a particular interest in a temporal perspective (Ancona et al. 2001). Development is at an initial stage in that there is a lack of understanding about how to build sustainable information infrastructures for scientific arenas (Jirotka et al. 2006; Spencer et al. 2006; Turner et al. 2006; Borgman 2007; Zimmerman 2007; Olson et al. 2008). We contend that scientific information infrastructure research and development poses a new kind of temporal challenge for the field of Computer Supported Cooperative Work (CSCW), namely that of the long-term.

With the fundamental aim of understanding how concerted action is achieved, CSCW research has studied collaborative activity across spatial and temporal dimensions. Though the canonical and previously widely used categorization of collaborative contexts along the axes of same/different and place/time (Johansen 1988) has been largely criticized (e.g. Schmidt and Rodden 1996) and even abandoned as overly simplistic (e.g. Reddy et al. 2006), space and time remain central themes in CSCW research. Temporality has-in retrospect-received far less attention than the issues of space, a situation paraphrased as "distance matters" in the widely cited article by Olson and Olson (2000). Though the problems of spatially distributed work have often taken analytic and technical precedence, "time also matters", as Reddy and collaborators have pointed out (Reddy et al. 2006). A tour of the CSCW literature on time (Section 3) reveals an emphasis on short-term timeframe issues. We argue that infrastructure development, in addition to growing in spatial scope and complexity (Olson and Olson 2000; Kaplan and Seebeck 2001), has grown in terms of multiplying and extending the temporal aspects of work involved in supporting broader-scale collaborations.

Cyberinfrastructure projects to date have largely been developmental efforts (Borgman 2007). Since the field is still in its infancy in many ways with development efforts typically funded as short-term projects, the majority of cyberinfrastructure undertakings studied have been short-range and in early phases of forming a research collective supported by an infrastructure. Despite this, some studies show a level of awareness of the long-term perspective inherent 
to infrastructures and their development (e.g. Zimmerman 2007; Lee et al. 2006), though few have directly addressed long-term as an infrastructure issue (Karasti and Baker 2004; Baker and Chandler 2008; Ribes and Finholt 2007, 2009). ${ }^{2}$ The research network with which we have a longitudinal involvement predates the cyberinfrastructure era, and thus allows us to study a more mature set of arrangements for long-term collaborative development of information infrastructure than present-day e-Science projects. In this paper we continue our exploration of the long-term perspective: from studying scientific information management with a focus on the stewardship of digital content over time (Karasti et al. 2006; Karasti and Baker 2008b), we return to addressing collaborative infrastructure development (Karasti and Baker 2004) with a more explicit interest in temporality.

We report on an empirical case involving the development of a metadata standard in a data-centric scientific domain, a complex example of infrastructure development as a long-term collaborative activity. Data-intensive-particularly referring to large in volume or computational demands - scientific collaboration is one of the heartlands of e-Science because data in digital form open new, appealing possibilities for large-scale research endeavors (National Science Board 2005; National Science Foundation 2007). The capacity for distributed, collaborative scientific work with data is posited on the existence of information infrastructures that support the coordination of data preservation, discovery and exchange (Hedstrom 2003; Arzberger et al. 2004; National Research Council 2007). Data-centric e-Research efforts, where infrastructure and information necessarily are intertwined, involve semantic work, i.e. the negotiation or creation of meanings and mechanisms for information organization through linguistic classification and development, and standard-making work, i.e. the development of procedures that informs determination of rules and requirements for classifications in order to improve consistency and interchangeability. Both semantics and standards are particularly prominent topic areas and essential types of infrastructure development work (Star 2002; Star and Lampland 2009; Hanseth et al. 1996; Jacobs 2006; Hine 2008; Randall et al. 2007, 2009). While there are many approaches and methods to semantic work, such as data dictionaries, controlled vocabularies, and ontologies (Baker et al. 2006a), our empirical case mainly deals with the development of a metadata standard. We investigate standardmaking efforts involving the integration of semantic work and associated software tools development as one aspect of collaborative information infrastructure development (Randall et al. 2007, 2009; Ribes and Bowker 2008; Schuurman and Balka 2008).

In our case, the domain of ecology is faced with both data-intensive (large in size or volume and computational requirements) and data-rich (diverse or large in number of different types) data challenges (Karasti et al. 2006). Data volume challenges relate to the contemporary 'data deluge', i.e. exponentially increasing volumes of primary data in digital form generated by automated collection and 
production of data through 'next generation' experiments, simulations, sensors and satellites (Hey and Trefethen 2003; Borgman et al. 2007). Challenges with data diversity, in turn, relate the intrinsic character of the field, i.e. the unusually heterogeneous and complex nature of ecological data (Bowker 2000; Baker and Millerand, forthcoming) that present daunting problems for interpretation and analysis (Zimmerman 2003). Ecological data, therefore, require intensive description and extensive contextualization in the form of metadata (Michener 2000; Jones et al. 2001) to be useful for the scientific purposes of collaborative research outside the place and time of their collection (Karasti and Baker 2008b). The use of standards in metadata description not only promises improved discovery and integration of the data but also automated access of importance to data-intensive research involving statistical approaches and data mining. The development of a metadata specification by a national center and its adoption by a research network as a standard has been described and discussed earlier (Millerand and Bowker 2008, 2009; Millerand and Baker 2010). This paper continues the narrative of the metadata standard as it unfolds today.

In our analysis, we use the term infrastructure as defined and conceptualized in Science and Technology Studies (STS). The notion of infrastructure by Star and Ruhleder (1996) is a multifaceted concept referring to interrelated technical, social and organizational arrangements involving hardware and software technologies, standards, procedures, practices and policies together with digital configurations in support of human communication and capabilities. In the context of cyberinfrastructure, the concept has been used, for instance, to study the social organization of distributed collaboration in 'big science' and 'big data' (Lee et al. 2006; Aronova et al. 2010). While Star and Ruhleder's (1996) notion of infrastructure does not encompass an explicit design interest, it is useful in sensitizing us to the relational, historico-socio-technical aspects of infrastructure development. We use it in describing and discussing the work that goes into collaborative infrastructure development for a long-term ecological research domain.

In this paper we foreground the issue of long-term that has been recognized but has remained a background concern of information infrastructure development. We argue that without awareness of the multiple temporalities and particularly the long-term temporal scales, studies of infrastructure development remain largely influenced by the prevalent, taken-for-granted short-term temporalities. We emphasize that an understanding of the long-term perspective is needed and will benefit and enrich the exploration of many other infrastructure development issues, such as emergence vs. intentional development, and openness vs. closedness of solutions. With this work we also begin opening up the window of time in order to extend the temporal reach of CSCW theories, concepts, methods and applications. Our particular interest is in the actual infrastructure development work carried out by different participants and the temporal aspects associated with their work. Thus we consider collaborative processes in different 
but related arenas over time; we observe the associated design practices and approaches as well as the participant's views using a temporal research lens (Ancona et al. 2001). For the purposes of the paper we use the widely used notion of 'temporal scales' (e.g. Zaheer et al. 1999) as well as the more specific one of 'temporal orientations' (Dubinskas 1988). We limit our focus to the short-term and long-term temporal scales in order to be able to present an analysis of a rich empirical study together with a theoretical discussion within the length of a journal paper. Using these temporal elements, we analyze our empirical case and identify two distinct 'temporal orientations' associated with collaborative infrastructure development: 'project time' and 'infrastructure time'. This paper presents an alternative perspective to the traditional view of short-term demands and long-term goals that are typically perceived as a tension. The tension is recognized as a crucial aspect of and challenge in infrastructure development (Karasti and Baker 2004; Ribes and Finholt 2007, 2009). However, rather than treating the differing temporal scales merely as a tension, this paper puts forward the interplay of the two as a synergistic approach to infrastructure development, as is exemplified in the 'infrastructure time' development orientation of 'continuing design'.

The following section provides theoretical background on the concepts of infrastructure and temporal scales with related research in Section 3. Section 4 introduces the empirical setting in an ecological research domain and our research approach of longitudinal involvement and interdisciplinary research strategy. Section 5 is devoted to presenting the metadata standard development study; it focuses on how the temporal scales of short-term and long-term are evoked, contested and blended in the process of collaborative infrastructure development work and elaborates on the differing views of the main parties involved. Section 6 discusses matters relevant to conceptualizing what is at stake in long-term infrastructure development work; it extends the notion of infrastructure and puts forward the temporal orientations of 'project time' and 'infrastructure time' and their related development orientations. Conclusions underscore the need to enrich understandings of temporality in both CSCW and e-Research and reveal the large extent of ramifications and challenges for all the associated stakeholders.

\section{Theoretical background}

\subsection{On infrastructure and its characteristics}

In common parlance, the term 'infrastructure' refers to large technological systems that are essential to human activities. Roads, bridges, rail tracks, and communication networks constitute the fundamental facilities and systems serving a country or city. In today's highly digitalized world, the term is also used to speak about constellations of software technologies and systems usually 
associated with the Internet, e.g. 'information infrastructure' and 'cyberinfrastructure'. Typical metaphors for infrastructure consist of ensembles of things (e.g. pipes, wires, and servers) that connect or transport people, fluids, signals, and such while staying in the background and being taken for granted in addition to being transparent to their users and becoming visible only in case of breakdown (Star and Ruhleder 1996). Research on infrastructure calls for changing common views and metaphors on infrastructure: from transparency to visibility and from substrate to substance. It requires 'going backstage' (Star 1999), studying infrastructure building 'in the making' (Star and Bowker 2002) and practicing 'infrastructural inversion' i.e. foregrounding infrastructural elements (Bowker 1994).

We draw on the conceptualization of infrastructure by Star and Ruhleder (1996) with related theoretical and methodological works (Star 1999; Star and Bowker 2002; Bowker et al. forthcoming). The notion has received growing interest, particularly in recent STS works on large-scale infrastructure developments in the sciences, e.g. cyberinfrastructure projects (Baker et al. 2005; Ribes et al. 2005; Karasti et al. 2006; Lee et al. 2006). Other efforts in the field have focused on deepening theoretical understanding of the notion (Edwards et al. 2007) and circumscribing information infrastructure studies as an emergent research area (Bowker et al. forthcoming; Edwards et al. 2009). Socio-technical aspects of infrastructure and their related ethical and political concerns are central in this literature where infrastructure is envisioned not only in terms of interdependent components (human resources, technologies, and organizational structures) but in terms of dynamic 'configurations' of communities, systems and organizations (Baker et al. 2005; Ribes et al. 2005).

Infrastructure studies encompass several key ideas. One central tenet is that an infrastructure is formed by the circumstances associated with the following dimensions: embeddedness, transparency, reach or scope, learned as part of membership, links with conventions of practice, embodiment of standards, built on an installed base, becomes visible upon breakdown (Star and Ruhleder 1996, p. 112-113). Another key idea is that infrastructure is both relational and practical: "[infrastructure] means different things to different groups and it is part of the balance of action, tools, and the built environment, inseparable from them" (Star 1999, p. 377). Infrastructure is relational in the sense that, "one person's infrastructure is another's topic, or difficulty" (Star 1999, p. 380). For instance, a plumber might see the waterworks system of a household connected to the city water system as a target object, rather than a background support (Star and Ruhleder 1996, p. 113). A systems developer might envision an application developed not as infrastructure - as a user might envision it - but as central. Infrastructure is practical in the sense that an infrastructure happens both "in practice, for someone, and when connected to some particular activity" (Star and Ruhleder 1996, p. 112). That is to say, another key understanding is that an infrastructure is always situated. 
Standards are key to infrastructures. More precisely, 'embodiment of standards' is a critical dimension of infrastructure: "infrastructure takes on transparency by plugging into other infrastructures and tools in a standardized fashion" (Star and Ruhleder 1996, p.113). Accommodated and instantiated in the 'middleware layer', standards appear as components of information systems at the same level as servers (hardware) or applications (software). But standards are also well known to play a critical role in the evolution of information and communication technology in general-just think about the Internet (Abbate 1999). Furthermore, standard-making and standardization processes are recognized to have technical, managerial, organizational, as well as economic aspects to them (see e.g. Lyytinen and King 2006 and other papers in the same special issue of MIS Quarterly). In this paper, we recognize and explore the metadata standard as a critical element in the development of research network infrastructure that crystallized significant tensions from competing temporal perspectives.

\subsection{On temporal scales and orientations}

Our common sense views on 'temporal scales' relate to durations of time, such as lunch hours, workdays, and funding periods. While there has been a substantial amount of research on time, researchers have rarely reached agreement (Adam 1990, 1994). For instance, temporal scales have been studied from both objective and subjective perspectives. According to the objective view, time scales are used to refer to absolute, quantifiable and measurable size temporal intervals independent of human action (e.g. Zaheer et al. 1999) such as chronos, clock and calendar time. From a subjective standpoint, temporal scales are seen as socially constructed, contextual, and relative to people's norms, beliefs and customs, such as kairos and 'instantaneous' time. Other examples include timeless time (Castells 1996), the 'duree' of daily experiences (e.g. day's work 'Tagwerk' (Adam 1990)), the 'dasein' of life or career time (e.g. Traweek 1988) or illness trajectory (Strauss et al. 1985), and the 'longue duree' of institutions and history (e.g. Brand 1999). In this paper we align with a gradually growing stance that sees the necessity of attending to both structural/objective and interpretive/subjective aspects of temporal order (e.g. Barley 1988; Orlikowski and Yates 2002; Reddy et al. 2006).

Temporal scales are diverse. In addition to the above examples of temporal scales relating to human/social systems, temporal scales dependent upon other 'actors' can be of importance such as those relative to nature's time or ecosystem change (Magnuson 1990; Foster and Aber 2004; Smith 2003) as well as those engraved in the built environment and associated with technologies such as railroads (Cronon 1991), electrical systems (Hughes 1983) and digital or IT systems ('Internet time'). With a particular interest in infrastructures, Edwards and colleagues put forward a temporal scale of 200 years that has been required 
for certain changes in society to have slowly taken place giving rise to information infrastructures and followed by the current development of cyberinfrastructures (Edwards et al. 2007). There is an increasing recognition of the diversity of temporal scales. For instance, in an analysis of time scales at play in settings of ecosocial systems education, Lemke identifies as many as 22 representative time scales for education and related processes that though lacking in specifics of technological timescales, range from chemical synthesis processes taking only fractions of a microsecond to time scales of seconds to years perceptible to humans to universal change spanning billions of years (Lemke 2000).

Temporal scales are described as situated or pertaining to particular settings. To be able to understand what temporal scales are meaningful in a particular social setting, one needs to study the everyday practices of participants with a 'temporal lens', i.e. putting temporal aspects front and center (Ancona et al. 2001). Participants in specific settings account for the meaningfulness of temporal scales in their social, technological and natural environment, hence temporal scales can be observed in participants' practices and views. For instance, Traweek highlights both beamtimes and lifetimes as consequential temporal scales in the world of high-energy physicists (Traweek 1988). Temporal scales are institutionalized through the production and reproduction of such practices, and temporal scales may, thus, vary under different conditions as participants shape and reinforce them to suit changing circumstances. An example from information systems design suggests that the temporal scales of systems designers in 'traditional' systems development settings have been adapted in alternative environments. For instance, shorter time periods are emphasized in the cases of agile, rapid or internet-speed software development (Baskerville et al. 2003).

Temporal scales are relational and they vary, for instance, for different participants as was highlighted through a study of the French republican calendar over 30 years ago by Zerubavel (1977). In a more recent study of biotechnology industries, Dubinskas has identified two communities of different occupations as professions contrasting in terms of temporal scales: company executives and research biologists. According to Dubinskas, the temporal scales for managers can be characterized in terms of short-range plans and closed-frame problem solving whereas scientists' temporal scales relate to more long-term, open-ended planning and problem solving. Based on these temporal scales, he identifies 'closed' and 'open ended' temporal orientations, respectively (Dubinskas 1988). Temporal orientations are thus temporal scales that relate to a group's understanding of meaning and value as well as to their interests, aims and motivation. While we acknowledge Orlikowski and Yates' critique pointing out that temporal orientations are not stable properties of occupational groups but an emergent property of attending to both open-ended and closed temporal element amidst everyday activities (2002), we explore these distinctions to more fully understand what is at stake and to conceptually further develop the notion of temporal orientation that we describe as 'infrastructure time' in our case. 


\section{Related research}

Within CSCW, temporal aspects of everyday work have been studied extensively, for instance, via studies of time management and temporal coordination (Egger and Wagner 1993; Bardram 2000; Crabtree et al. 2003; Reddy et al. 2006) and via investigations of rhythms, patterns and temporal trajectories (Reddy and Dourish 2002; Sandusky 2003; Seebeck et al. 2005; Nilsson and Hertzum 2005). Furthermore, temporal aspects of collaboration have been analyzed in relation to a number of collaboration technologies such as email (Tyler and Tang 2003) and groupware calendar systems (Lee 2003; Crabtree et al. 2003). There are a few studies that show interest in longer timeframes including articles highlighting aspects of long-term interaction in office work (Dix et al. 1998), the need to bridge the gap between face-to-face communication in long-term collaboration (Lindstaedt and Schneider 1997), the necessity to consider both real-time supervisory control work and differently paced design work (Sandusky 2003), and long-term collaboration in software maintenance (Lougher and Rodden 1993). Nevertheless, it is interesting to note that 'long-term' temporal scales in these studies refer to rather short-term timeframes, such as "hours, days or even weeks" (Dix et al. 1998, p. 9), "during different phases of a project" (Lindstaedt and Schneider 1997, p. 331), and "daily periods", "weekly cycles" and "windows of time (during weekends and holidays)" (Sandusky 2003, p. 101). Only Lougher and Rodden acknowledge longer timeframes in relation to software maintenance work "extending over a period of many years with some systems even being in use for in excess of two decades" (1993, p. 229). Correspondingly, durations of multiple years and decades found in our case study are relevant to the notion of 'infrastructure time', extending beyond moments of conversational turn-taking, workdays and work weeks that traditionally represent the long-term in studies of everyday interaction and collaboration.

Further, the notion of collaboratory used widely both in CSCW and cyberinfrastructure studies of scientific collaboration (e.g. Sonnenwald 2003; Finholt 2002; Olson et al. 2008), has a spatial-specific cast. Collaboratories were initially defined as "center[s] without walls in which researchers can work together regardless of physical location" (Wulf 1993). A more recent definition continues with a focus on spatial distribution and interest in real-time interaction in stating: "A collaboratory is an organizational entity that spans distance, supports rich and recurring human interaction oriented to a common research area, and provides access to data sources, artifacts and tools required to accomplish research tasks." (Olson et al. 2008, p. 3). The typology of collaboratories (Bos et al. 2008) focuses on different ways of creating largescale organizational structures for scientific collaboration, and from the temporal point of view usually differentiates between synchronous and asynchronous modes of collaboration.

In the field of information systems at large, collaborative development work is typically organized as projects (see e.g. Avison and Torkzadeh 2008). In projects, 
time is traditionally viewed as a scarce resource of measurable clock time to be ordered through design methods and models delimited by project management which in research and development (R \& D) settings relates to periods of funded project time. However, such formal approaches based on a mechanistic model of work appear inadequate to manage team members' practices in contemporary working environments (Nandhakumar 2002). A number of studies have made visible the multitude of temporalities involved in the actual practices of information systems development (Nandhakumar and Jones 2001; Nandhakumar 2002; Stacey and Nandhakumar 2009; see also Bucciarelli 1988). Furthermore, a study of software development in the Internet environment shows how developers' approaches, methods and practices are formed in relation to the temporal characteristics of the Internet industry. Thus, software development associated with web delivery emphasizes shorter cycle times and introduces shorter than traditional temporal scales known as internet-speed or web-speed (Baskerville et al. 2003). Infrastructure development has not yet received similar temporal interest, though related issues such as standardization vs. flexibility, global vs. local, and small-scale vs. large-scale (Hanseth et al. 1996; Monteiro 1998; Rolland and Monteiro 2002), have been investigated.

The suggestion to transform 'infrastructure' into a transitive verb as initially proposed by Star and Bowker in an article asking "How to infrastructure?" (2002), prompted a stream of research (e.g. Karasti and Baker 2004; Karasti and Syrjänen 2004; Edwards et al. 2007; Pipek and Wulf 2009; Baker and Millerand, forthcoming) investigating development processes in terms of 'infrastructuring'. Incremental, iterative processes, discerned as 'growing' over time, contribute to questioning whether infrastructures can be built at all in the traditional sense of technology development (cf. Freeman 2007). Traditional measures of size in terms of numbers of participants and systems or of computational cycles and storage units are not taken as the most important denominator of infrastructures; rather infrastructural systems and their integration are the focus (Hanseth and Lundberg 2001; Karasti and Syrjänen 2004; Pipek and Wulf 2009). Some of these studies draw on previous research on continuing design in use (Henderson and Kyng 1991) and tailoring (Trigg and Bødker 1994), and later work on appropriation (Pipek 2005) with roots in the Participatory Design tradition where development is seen as taking place over time. Yet, these approaches of 'infrastructuring' deal with long-term processes and related problematics implicitly rather than with explicit analysis of the temporal.

Within Science and Technology Studies, long-term temporal scales are common and studies may span long historical periods. Seminal works on largescale technological systems providing broad level, policy-oriented historical analyses demonstrated the need to pay attention to innovation processes over the long-term to understand major technological developments and institutional changes (Hughes 1983). More recent works within STS looking at information infrastructure development consider time as a base-level tension that adds 
complexity to the work of infrastructure building - when short and long-term funded projects don't suit the even longer time scales over which infrastructures typically develop and take hold (Edwards et al. 2007). "The time scale in historical studies of infrastructural change is decades to centuries - considerably longer than most research projects in cyberinfrastructure!" (Edwards et al. 2007, p. 8). Ethnographic studies argue for paying attention to the diverse temporalities of all the involved actors (e.g. scientists, information technology specialists, informatics researchers, data specialists, communities, funding agencies) as an alternative to viewing infrastructure growth in sequential phases, e.g. emergence, maturation, loss of impetus and so on, according to linear time (Millerand and Bowker 2009). Following Latour (1996), it is argued that "time is a variable, not an explanatory framework for the phenomenon under consideration" (Millerand and Bowker 2008, p. 280). Such a perspective on time allows one to "better grasp how the existence and even the reality of projects vary over time, in line with the engagement or disengagement of actors in the development of these projects or objects" (Millerand and Bowker 2009, p. 151).

Much of the STS oriented research on cyberinfrastructure has investigated the organization of large-scale, multi-institutional undertakings developing both social and technological infrastructure. Focus is on the commonly identified difficulties, such as communication, collaboration and coordination, in the new organizational structures that serve geographically distributed collaborations (Olson and Olson 2000; Finholt 2002; Lawrence 2006; Lee et al. 2006). From the point of view of long-term temporal scales, the work by Ribes and Finholt (2009) offers an interesting exception. They utilize Stuart Brand's concept of 'the long now' as a conceptualization of time that demands sustainability become of central concern today. Infrastructure development may be seen as an occasion for 'the long now': "it is a concept that collapses immediate design and deployment with the work of maintenance and sustainable development" (Ribes and Finholt 2009, p. 393). Through an analysis of participants' formulation of the problems encountered in developing long-term information infrastructure, Ribes and Finholt identify a set of tensions in order to delineate "the problem space in which choices about information infrastructure design are made" (p. 393). In such a 'problem space', we analyze the actual practices and concrete ways that participants in a particular endeavor have developed over time for dealing with long-term collaborative infrastructure development.

\section{Empirical setting and research approach}

\subsection{An ecological research domain}

The empirical case in this paper is situated within an ecological research domain. The infrastructure development in this study may be identified as collaborative work that occurs in three arenas: (1) a national center for the domain of ecological sciences, (2) an ecological research network, and (3) individual research sites that 
constitute the research network. The main parties associated with the infrastructure development of interest are developers at a national center and information managers located at sites within the research network. The national center in question is the National Center for Ecological Analysis and Synthesis (NCEAS), and the research network is the US Long-Term Ecological Research (LTER) Network.

The US LTER is a network of research sites carrying out ecological research collaboratively according to the LTER program and traditions. The LTER program was funded by the US National Science Foundation (NSF) with the idea of scaling up both spatially and temporally from typical small-scale and short-term ecological studies (Hobbie et al. 2003). Long-term ecological research spans diverse spatial and temporal scales, recognizing historical change as a key to understanding the present and anticipating the future (Callahan 1984; Magnuson 1990). The timeframes involved in long-term ecological research are illustrated by 200 1,000 year experiments (Harmon et al. 1999; Smith 2003; Foster and Aber 2004). Since establishment in 1980, the research network has been supported by NSF long-term funding arrangement. Sites are selected to become part of the LTER program through competitions held by NSF. After the initial competition, they no longer compete against one another; rather, each site is evaluated every six years for continuation and renewal of funding.

The 26 research sites that currently form the research network study their particular local biomes, i.e. climatically and geographically defined ensembles of communities of plants, animals, and soil organisms, often referred to as ecosystems. The sites design their own field measurement programs, collect long-term time series data, and take responsibility for the management of research data produced locally. Aligning with the aim of the research network to create a legacy of well-designed and documented long-term experiments and observations for use by future generations, many sites have legacy data going back well over a hundred years. Data management has been an integral part of the research network since its inception, and its importance has grown to be described as information management (Baker et al. 2000). The data-rich nature of ecology and the work associated with long-term datasets together form the very foundation for long-term ecological research. Consequently, the timeframes of information management intertwine with those of long-term ecological research, legacy datasets, and expectations of future reuse, effectively extending the temporal scope and thereby the perspective of participants from the past well into the future.

In addition to being charged with the care of data, site information managers are also responsible for the development and maintenance of local infrastructures. Thus, each site has its own practices and arrangements for data management including a data repository and local software tools. Though anchored at their sites, information managers have developed an all-site forum called the Information Management Committee that forms a 'Community of Practice' 
(Lave and Wenger 1991). This collective forum offers them an opportunity to learn from each other's experiences with diverse local arrangements as well as to collaboratively develop information infrastructure for the research network (Karasti and Baker 2004; Karasti et al. 2006). In recent years, a new urgency has been introduced by cyberinfrastructure efforts; the information managers have become challenged to change from their established ways that support data use for site-based research to collaborate on infrastructure efforts that enable wider community and public (re)use of the data. This new work is largely predefined by participation in large-scale, multi-institutional cyberinfrastructure initiatives with network partners including national centers (Cushing et al. 2005; ARL Workshop in New Collaborative Relations 2006). Following the documentation of the concept of non-spatial metadata by a committee within the Ecological Society of America (Michener et al. 1997), development of the metadata specification, i.e. the Ecological Metadata Language (EML), was proposed to NSF as the Knowledge Network for Biocomplexity project. The research effort was funded for three years (1999-2002) and centered at NCEAS. Development of the metadata standard brought LTER information managers together with NCEAS developers.

With this case study, we are presenting a snapshot of a research network gradually unfolding over three decades (1980-ongoing) that highlights semantic work and associated software tools development as a crucial part of the infrastructure required for data-rich collaborative ecological research. The metadata standard in question is a specification for describing ecological datasets so that they can be understood beyond their point of origin and place of initial processing. Metadata are structured statements about other data, in this case about primary observational data, and a standard defines the structure and elements that provide the information needed by other researchers for interpreting correctly the data. For instance, in a simple case, metadata for a dataset would include a dataset title, keywords, abstract and owner name as well as the names and units of each variable. While with a few thousand datasets such indexing work may appear mundane at a research group or laboratory scale, the complexity of this work explodes. Larger assemblages of datasets, needed for interdisciplinary research where data cross-disciplinary domains, space and time, make a comprehensive metadata standard elusive. A metadata standard would need to provide a structured yet harmonized framework for describing diverse data at increasing levels of detail needed for enabling data discovery, access, query, integration, exchange, and comparability. In the case we study, a metadata standard would enable queries for data discovery and comparability to be made across all research network sites' datasets seamlessly, and ultimately across those within the domain of environmental sciences.

\subsection{Longitudinal involvement and interdisciplinary research strategy}

Our collective research approach can be described as long-term involvement, necessary because the investigation of infrastructure requires long-term commit- 
ment. This is supported by interdisciplinary partnerships that include membership in and experience with the research network, information management, science and technology studies, computer supported collaborative work, participatory design, workplace studies and that foster ongoing learning upon which this paper draws.

Our collective research environment supports the study of longer temporal scales in, at least, three ways. First, we have had the rare chance to be involved with and studying the US ecological research network in question for a number of years. Baker has been a practicing researcher since 1990 when the first of the two sites for which she is an information manager started in the network. Karasti did fieldwork within the US research network in 2002 and has continued participation in and study of long-term ecological research at different organizational levels and geographical regions including international, European and Finnish networks. Millerand carried out fieldwork within the same US research network starting in 2004 and continues studying it, notably the information management community as well as the development of cyberinfrastructure and standards. As a result, we have formed longitudinal understanding(s) about the empirical setting. Second, the research network has existed for three decades, and thus provides a relatively mature setting to be studied. It is a research network with history, culture, customs and infrastructure arrangements predating the cyberinfrastructure era; it has various trajectories of change as well as ongoing change processes. Third, the research network itself is profoundly oriented towards the long-term perspective, both in science, information management and infrastructure work. This provides opportunities to study the ways and methods that network participants have created to deal with the complexities, concerns, and constraints inherent to the long-term temporal scope of its core interests and activities.

The empirical data for the research reported in this paper were collected by Millerand and Baker within the research network from 2004 to 2006. During this two year period, they conducted 15 interviews, attended meetings about the metadata standard (e.g. working groups), participated in numerous discussions and phone calls about the metadata standard and related topics, and made frequent observations on the standardization process across the LTER sites. Corpus for document analysis included proposals, surveys and reports including articles in the information manager newsletter, technical documentation (e.g. EML Best Practices) as well as tool prototypes and demos.

Our individual empirical work within the long-term ecological research network(s) and subsequent shared - yet also differently positioned - understanding(s) have allowed us to carry out research and analysis as a distributed team. Our distance collaboration has been supported by Internet technologies such as conference calls, email and shared workspaces. We first discussed several possible interesting cases from each of our three distinct experiences with the fieldwork. The metadata standard case emerged quickly as interesting because it showed salient temporal issues. Since only two of us have been closely involved 
with the case, we built a detailed narrative from which we could work and carry out new analysis focusing on temporal dimensions. During analysis sessions we have talked and shared interpretations about the empirical data in considering how different temporal scales are woven into the practices of and participants' views about infrastructure development work. Also, we have drawn broadly upon our experiences within the empirical setting over the long term.

Our collective research approach is based on an interdisciplinary research strategy where we pooled and modified our theoretical and methodological frameworks to be able to grasp the complexity and the expanse of infrastructure development. Unlike a multidisciplinary approach that would address infrastructure development from independent disciplinary points of view-thus leading to the production of distinct discourses with the risk of a research object being parceled out, we engaged in an interdisciplinary approach by aiming at developing a common conceptual framework - thus expanding our existing disciplinary-marked research perspectives (Klein 1990). For instance, the combination of information management insights and attention to science and technology ethnographic perspectives was critical in carrying out the detailed analysis of standards development as it occurred. Further, bringing participatory development into the analysis highlighted aspects of standard-making as collaborative infrastructure development. Integration of STS with interdisciplinary works on time research significantly opened up our understanding of the temporal issues at play in collaborative infrastructure development.

\section{Empirical study}

This section describes the collaborative process of developing and implementing a metadata standard and related tools, with a focus on the temporal scales of short-term and long-term. Figure 1 summarizes the key elements of the case description. Section 5.1 sets the stage with a few chronological elements. Section 5.2 describes the project to develop the metadata specification at the national center, its adoption as a standard, and subsequent attempts to implement it in the ecological research network. Section 5.3 explains the continuing development of the metadata standard by the information managers located at sites within the ecological research network. Presentation of differing temporal views of main participant groups completes the empirical study section (Section 5.4).

\subsection{Setting the stage}

Metadata work went on within the research network throughout the 1990's. For instance, a network catalogue or list of dataset descriptions could be created because the sites had in place metadata forms as an integral part of managing their scientific data. The forms, however, were formalized in diverse ways, thus 


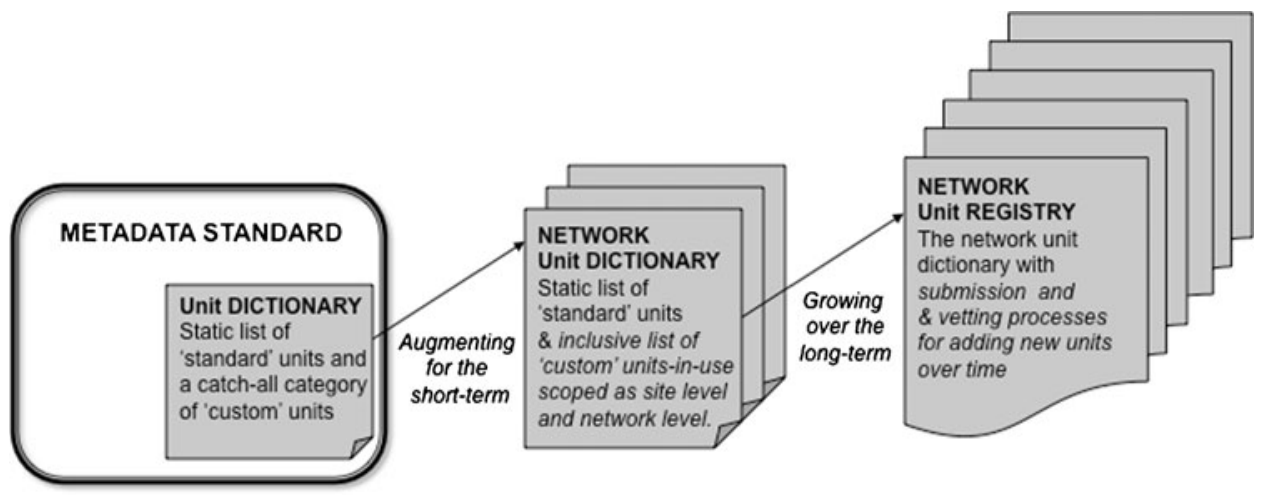

Figure 1. Continuing development from a Unit Dictionary as part of a metadata standard to a Network Unit Dictionary to a Network Unit Registry.

limiting metadata sharing through the research network. In 1996, the inauguration of a project to develop a research network wide information system (Brunt 1998; Baker et al. 2000) stimulated discussions about standardizing data management procedures and encouraged the development of common tools for the information managers. It is from this context that the project to develop a metadata standard emerged and became the focus of research projects by a consortium of partners including the national center.

At the national center, development of the metadata standard begins in 1996 with awareness of the value of a domain-wide standard for the whole of ecological research. Version 1.0 of the standard was released in 1997. Several versions of the standard and related software tools were developed within an 'open' development arena. In 2001, a stable version (version 2.0) was released and presented to the research network. A consensus decision was made to adopt the metadata standard in order to enable data discovery and reuse. At the annual meeting of information managers in 2005, progress was seen as somewhat mixed. The standard implementation was still ongoing and seen as a complex and laborious process (Millerand et al. 2005). In 2009, there is full site participation in terms of capacity to submit standard compliant datasets to a centralized metadata catalogue of the research network but metadata related work related to fuller functionality is still underway both at sites and at the network level. Ramifications of adopting the metadata standard are still driving site change and innovation.

\subsection{Development of the standard}

5.2.1. 'Potentially universal' in the long-term yet 'ready-to-use' for the short-term

The main objective of the developers of the metadata standard located at the national center involved a domain level goal: to develop a universal standard 
valid for ecology. The intention was to create a metadata specification fulfilling ecological research needs with an interim goal of having it adopted as a standard by selected networks within the domain. Adoption would provide recognition of its usefulness and demonstrate its potential as a standard for the larger ecological domain. Adoption would also signal a positive end of the project in terms of a successful deliverable provided within the funded project timeframe. Completing a stable version of the specification in 2001, developers envisioned the specification as a potentially universal standard in the long term and, at the same time, as a suitable ready-to-use standard for current needs of the research networks and the larger domain of ecological research (Jones et al. 2001; McCartney and Jones 2002; Fergraus et al. 2005). In Star and Ruhleder's words about infrastructure properties, the standard would "reach beyond a single event or one-site practice" (1996, p. 113), aiming at gaining the reach and scope of an infrastructure element.

As implementation of the standard began across the ecological research network, tensions crystallized and issues arose as the ramifications of introducing the standard in local settings gradually emerged (Millerand et al. 2005). Sites ran into difficulties: the standard was complex and difficult to understand in its entirety. The technical tools intended to facilitate its implementation proved largely unusable at the sites, i.e. incompatible with existing local site data practices and infrastructures. In general there ensued a large amount of illdefined, unanticipated work at all levels - from conceptual design to financial support - that was added to the normal workload with minimal new resources provided for planning or for development. That is, it took some time before it was recognized that implementation of the standard entailed additional activities, such as the modification or redesign of existing site data practices and information systems as well as the development of new network practices and applications addressing multi-site coordination requirements (Baker and Millerand 2008). Thus there was need both to modify local practices and to augment the standard.

In practice, the (universal) standard had to be understood and implemented at each (singular) site in order to be used within the ecological research network as a whole. The information managers had to juggle short and long-term concerns and constraints while engaging in implementing the metadata standard. From a shortterm view, they had to coordinate across the sites a common interpretation of key concepts incorporated in metadata standard such as what constitutes a 'project' ${ }^{3}$ (a site with all its associated datasets that may be related to multiple field campaigns and investigators) and a 'dataset' (a set of tables with each table recording a set of related measurements with specified units, having similar methods and sampling design as well as related in terms of collocation in geography and time). As an example of alternate interpretations, research sites had described a 'project' as the datasets from a one-time field study, a three-year funded research project, or a single long-term monitoring deployment. Each site had to modify existing data management practices to be able to produce the 
agreed upon metadata. From a long-term view, the information managers needed to extend site metadata content as well as to create or redesign mechanisms for metadata production (Baker et al. 2006a).

Information managers gradually discovered that in addition to the above described contextualization work related to modification of local metadata practices in order to create a shared interpretation of the metadata standard, successful implementation also required an augmentation of the standard. As an illustration we describe here an example that will be elaborated in Section 5.3. The example concerns measurement unit descriptions that were provided with the metadata standard but turned out to be too narrow a set to be useful in practice. They consisted mainly of standard or 'universal' units (e.g. 'second' for time or 'milliliter' for amount of substance) whereas a majority of measurement units in use in ecological research were designated 'customized units' (e.g. 'MilligramsOfCarbonPerMeterCubed' for production and 'NumberOfEggsInNest' for reproductive success). As full metadata description of a dataset requires specification of the unit for each measurement variable, information managers realized they would have to create a new approach in the form of an application that would augment the metadata standard capacity in terms of well-documented unit descriptions needed to create well-described data. This limitation exemplifies the situatedness of infrastructure as well as an inherent tension between local and global where the expectation is that 'local' practices are to be afforded by a 'global' technology in a natural manner, and, at the same time, where infrastructure has to take on transparency and to plug into other infrastructures in a standardized way (Star and Ruhleder 1996). In this case, the standard would have to be augmented so that it could support local practices at a site level (a central concern for information managers) while being able to plug into other infrastructures and tools in a transparent way at a domain level (a central concern for the developers).

\subsubsection{Short-term biases in design}

The design approach adopted by developers at the national center followed an open development process based on a collaborative effort with voluntary participation offered to ecological research communities. Though initially the product of a specialist in ecological informatics working with staff members and doctoral students, a broad participation, especially from the research network's information managers, was expected because of the open-door invitation. The initiative, however, largely failed to engage many information managers mainly due to an incompatibility of working timeframes and resources. Developers were used to working at a distance, interacting frequently with use of chat tools, spending hours a day working on and communicating about the standard. Engaging with the developers' team meant being able to join the form and pace of real-time exchange. Allocation of time at the developers' tempo of meeting 
routinely and frequently was something that the information managers were unable to do within the informal role of volunteer participants or ad hoc members. Given the daily involvement of the developers, progress was fast, 'like a fire-hose', and it was almost impossible for the information managers to stay up-to-date and to participate in the ongoing development process. In other words, developers at a national center used a design process that was open in theory but closed in practice given the singular emphasis on real-time participation. The short-term bias can be considered an example of a lack of collaborative design methods for engaging multiple participant groups with divergent timeframes; that is, considering possibilities for alternative temporalities in development would enable collaboration.

\subsection{Continuing development of the standard}

In this section, we describe the collaborative development by the information managers of two tools that would work in coordination with the metadata standard and would facilitate implementation of the standard at sites. They, in effect, continued the metadata standard-making process - but at the site and network level instead of at the domain level - through work on a network unit dictionary and a network unit registry. These examples of collective tool development represent 'augmenting for the short-term' (the network unit dictionary) and 'growing over the long-term' (the network unit registry) (see Figure 1). Both examples illustrate in-practice innovation (cf. situated innovation, Dittrich et al. 2009) in that - in struggling with diversity and attempting to create consensus - they draw upon the inherent configuration and characteristics of the networked organization with local sites and rely on incremental inclusion made possible by the continuity of the research network. Short-term and long-term concerns are incorporated into information managers' continuing design effort, effectively combining the temporal scales traditionally perceived as at odds with each other.

\subsubsection{Response in the short-term: augmenting a network unit dictionary}

Once the standard was adopted, a collective initiative to develop a tool-a network unit dictionary-emerged in the midst of the difficulties encountered in metadata standard implementation. The information managers recognized the dictionary content as a critical limitation of the unit dictionary packaged with the metadata standard because the dictionary contained only a set of physical units whereas ecology is well-recognized as involving a diversity of biological observations and measurements with a large number of different units; in fact, physical measurements represent only a fraction of the data recorded. They conceived of a 'network unit dictionary' as a metadata standard 'related tool' that could be developed to augment the existing unit dictionary two-category system 
for describing the types of units: 'standard' or 'custom'. The former indicates that the unit can be found in the unit dictionary of the metadata standard while the latter indicates it is not in the metadata dictionary. One of the challenges for information managers was to address the ambiguity introduced by the 'custom unit' category, an ambiguity that is a serious barrier to the goal of data integration. Since the work of unit identification by matching with entries in the unit dictionary is not carried out for custom units, information important to data use and particularly to data integration is not available. A large number of the units used at the research sites fell into the catch-all category of 'custom unit'. In short, the development of a network unit dictionary listing all units for data collected at sites of the research network was launched. The network unit dictionary was developed collaboratively, and it proved useful in the short-term as a coordinating device: making available a publically controlled list of custom units to which individual research sites could compare their own units. The dictionary made visible the contents of the opaque, ambiguous category of 'custom' in the metadata standard. Initially a subset of sites communicated periodically about their handling of units. Units were aggregated, a web application developed and a prototype demonstrated at an Information Management Committee meeting in 2005 (Baker et al. 2006b). A working group convened subsequently continued by launching work on a Unit Best Practices effort. During development, exchange of information occurred about experiences with identification of non-standard units, site methods used in managing units, and understandings of how units were organized within the metadata standard.

\subsubsection{Viability over the long-term: growing a network unit registry}

In time the notion of a network unit dictionary expanded to include a 'network unit registry' as the new concept of 'scope' emerged from the dictionary dialogue (Baker et al. 2006b). The scope represents a mechanism for defining the acceptance level of a specific unit while allowing the status to change over time. Multiple levels of scope were considered with two levels finally adopted: 'site' indicating that the unit was used at and contributed by a site and 'LTER' indicating that the unit was accepted at the research network level. The 'site' scope was assigned at the moment of submission of a new unit by a site.

The process of moving between the two levels of scope was given the name 'vetting'. The network unit registry represents a collaborative tool supporting change through a review process. In essence, the existence of a 'site' designation ensures immediate acceptance and visibility of a local site unit in a network digital commons; it is the first step in creating a new unit dictionary entry. The vetting process prompts contributors to discuss whether a unit is (or could be in the future) a local site-specific unit or an all-site network unit. In so doing, the immediate need for recognizing and gathering site units occurs without delay or impedance to site work so that specific local metadata becomes coordinated with 
research network metadata with respect to units. Meanwhile, the long-term need to explore and resolve differences in units is addressed through assemblage and comparison by unit submitters. This development process recognizes and allows for the complexity of the undertaking and is still evolving.

In response to the need to open for scrutiny the 'custom' unit category in the metadata standard and to create a network unit dictionary gathering units-inuse, information managers developed the concept of 'scope' with identified levels of acceptance for units. 'Vetting' is being designed as a process to facilitate management of the status of a unit as it moves between levels. The temporal dimension manifests in an awareness of the long-term, starting with the existing units of the 'installed base' (Star and Ruhleder 1996) and recognizing a need to plan for the future by creating tools that support the process of growing a unit dictionary over time by including not just current units but planning for units that will need to be changed or that will emerge in the future and need to be added.

In these two cases of tool development, information managers drew upon their accustomed, shared methods and practices of collaborative infrastructure development, an approach that has been described as Community Design (Karasti and Baker 2008a). Implementation of the standard and subsequent inpractice innovation in the ecological research network might not have been possible if information managers did not have a legacy of common experiences with a collaborative approach and associated methods that are proven, shared, and improving over time. In addition to the use of traditional methods of networked organization, e.g. mailing lists, research network surveys, working groups, white paper generation and collegial sensitivity to difference, information managers have developed methods that enable collaborative development while minimizing disturbance to ongoing practices, e.g., 'learning through collaboration-in-design', 'cherry-picking', 'prototyping into consensus', and 'identification of minimum sets of requirements' (Karasti and Baker 2004; Karasti et al. 2006). In these methods relations between sites are characterized by an understanding of the importance of dialogue about similarities and differences both as learning opportunities and as a way for informing research network decision-making (Karasti and Baker 2004; Karasti et al. 2006). Furthermore, practices have evolved to ensure that time is devoted to network level concerns through attention to development of informal and formal communications, a tradition of participation by every site in the Information Management Committee, and a legacy of collaborative work that allows for extended periods of time for gaining the inclusion of all sites in the research network (Karasti and Baker 2008a).

\subsection{Differing temporal views and orientations of participant groups}

While the previous sections have described the practices of developers and information managers, this section takes a closer look at the temporal views of 
collaborative infrastructure development held by these two parties. We link these views with Dubinskas' notion of temporal orientations (1988) and identify two temporal orientations: 'project time' and 'infrastructure time'.

\subsubsection{Developers' 'project time'}

The temporal orientation of 'project time' can be characterized through the practices and views of developers as they develop the metadata standard. While their temporal orientation varies between open-ended and closed amidst their everyday activities (Orlikowski and Yates 2002), it becomes closed every time a project comes to an end in order to accomplish and delineate promised results (cf. executives' temporal orientation in Dubinskas (1988)). As there are typically several loosely associated projects, both consecutive and overlapping, successive periods of 'beginnings and ends' abound and developers frequently need to engage in closed temporal orientation to be able to deliver promised results and products within funded project time. For instance, in considering the question of unit dictionary for the metadata standard, the developers adopted a two category solution: 'standard' and 'custom' units because they needed to finish the product (the metadata specification) that would bring successful completion by project end. As the issue of units quite unexpectedly emerged late in the project, the developers reviewed and assessed existing approaches, after which the physical standard units solution was chosen because it included a well-known classification scheme for measurement typology and a custom category could be included to act as a catch-all category for the rest of units. In 'project time', near-term plans and closed-frame problem solving are linked to the short-term funding cycles of a project-based organization. As exemplified here, the developers resolved the tension between short and long-term in technology development within 'project time' demonstrating that their temporal orientation is necessary and suitable for their project-based work environment.

From the perspective of developers working within project timeframes, the scope of information managers' plans is too long for project-based research and development efforts. Further, developers would see the processes of incremental outcomes, such as in the case of information managers developing the network unit dictionary and registry, as encompassing a seemingly infinite process into a vague future with no finished product in sight. This open-ended approach to collaborative infrastructure development is seen as unrealistic. According to developers, work 'realism' in the realm of standards has necessarily to do with short-term considerations, including R \& D project funding.

\subsubsection{Information managers' 'infrastructure time'}

The temporal orientation of 'infrastructure time' becomes visible through information managers' practices and views as they use, modify, and further 
develop the adopted metadata standard. Information managers' temporal orientation is similar to that of the developers in that it varies between open-ended and closed amidst everyday work activities (Orlikowski and Yates 2002). Yet, it is different in that it favors an open-endedness much like the scientists' temporal orientation in Dubinskas (1988) in the sense that there exists an awareness of the continuity of development efforts and an understanding that the data cannot be abandoned in turning to new technology development efforts. The case provides an example of information managers' open-ended temporal orientation and practice of handling the short-term while also working for the long-term.

For the data practices and infrastructure development work of information managers within this data-focused scientific network, open-ended planning and processual, long-range problem-solving are linked to decades of shared experience gained in and through working collaboratively on information management and infrastructure development within an environment with a long-term perspective, that is the research network's scientific program and its sustained funding. Information managers employ collaboration methods that allow for long-lasting open-ended intervals, such as for gaining the inclusion of units over time and of all sites to be able to submit metadata standard compliant datasets to a network metadata catalogue. The tension between different temporal scales is resolved when both short-term and long-term are attended to within 'infrastructure time' where a short-term solution (the existing unit dictionary packaged with the standard) is viewed within an infrastructure time trajectory of continuing development of a short-term tool (the network unit dictionary) and the design of a long-term update process enabling addition of units and vetting of entries (the network unit registry). In the work of information managers the longterm does not appear as an isolatable issue, rather it is a specific concern that is continuously attended to and accounted for as a part and parcel of their ongoing, everyday work.

From the perspective of the information managers, the work of developers is seen as 'short-sighted': mired in generalizing for 'universal' or multiple audiences and short-range project concerns with here-and-now political declarations of 'products finalized in time'. For information management work at a longterm research site, it is essential to mediate between the open-endedness of scientific work, ongoing nature of data management, and the short-range planning inherent to work with technology and with associated short-term projects. Consequently, information managers balance the short-term and the long-term concerns of data and infrastructure that are central to research sites involved in extensive data-taking efforts; they tend to devalue single-minded development of an isolated application especially by those with no data of their own. Information managers' infrastructure work is not organized on a project basis, but supports and interacts with ongoing projects. Dashes to a goal-line solution are experienced as disruptive of complex arrangements of sociotechnical balances and data flows existing at the sites. 


\section{Discussion}

In this section we propose an extension to the infrastructure concept in terms of explicit inclusion of a temporal dimension (Section 6.1) and discuss further the temporal orientations of 'project time' and 'infrastructure time' (Section 6.2) as well as related development orientations (Section 6.3). By juxtaposing the two temporal orientations with related development approaches, we aim to highlight how the newly identified infrastructure time differs in important ways from the more prevalent and well-known project time.

\subsection{Extending the infrastructure concept with temporal scales}

Following Star and Ruhleder (1996), an infrastructure emerges when it reaches beyond a single event on a temporal scale or a single site practice on a spatial scale. In our analysis of collaborative infrastructure work, we focus both on the spatial scope and temporal scope of infrastructure. We tease out the less-explored temporal dimension relating to a multiplicity of temporal scales, short-term and long-term in particular. With regard to the spatial scale, Star and Ruhleder (1996, p. 114) state:

An infrastructure occurs when the tension between local and global is resolved. That is, an infrastructure occurs when local practices are afforded by a larger-scale technology, which can then be used in a natural, ready-to-hand fashion. It becomes transparent as local variations are folded into organizational changes, and becomes an unambiguous home - for somebody.

We argue that a similar observation can be made about the temporal dimension of infrastructure. To account more explicitly for the temporal dimension of infrastructure, we would say:

An infrastructure occurs when the tension between short-term and longterm is resolved. That is, an infrastructure occurs when here-and-now practices are afforded by temporally extended technology that can be used in an everyday, reliable fashion. Infrastructure becomes transparent when it exists as an accessible, ready-to-hand installed base that enables envisioning future usages.

From the point of view of infrastructure lifetime, it is necessary that short-term temporal scales (day-to-day data organization and information technology work) are balanced with long-term requirements (information infrastructure growth, inclusiveness, maintenance, and redesign). From the point of view infrastructure development, infrastructures do not 'occur' in practice when developers are deliberately able to resolve the tension between short-term and long-term, ${ }^{4}$ although it may very well serve as a sound principle underlying infrastructure design strategies and methodologies. Furthermore, infrastructure development is 
not only an intentional activity, an emergent element is always - particularly over the long-term-involved.

From the point of view of our case, infrastructure development implies working both with short-term and long-term timeframes, e.g. in answering immediate user needs and making data available to scientists through a local data system while also anticipating future needs or constraints and preserving data for archive or reuse. There is an understanding that the data formats, structures, and nomenclature currently in use in an individual scientist's lab frequently aren't suitable for exchange or reuse purposes. Idiosyncratic data labeling would have to be transformed in favor of more universal conventions and details on data collection methods or measurement units would have to be included in the data's metadata. Also, applications and software that would be useful to build up and use at a particular moment of infrastructure development might not be as useful in the long run, or even, might become strong obstacles to further development. Yet, they would have been necessary and appropriate for specific purposes and for particular timeframes, e.g. to safeguard funding, to address technical issues in a timely manner or to answer a user group momentary need. Furthermore, some aspects of infrastructure may emerge as work-arounds, e.g. use of an extra field in metadata description for storing user feedback may grow into a recognized category used across the community.

There are additional temporal aspects implicit to Star and Ruhleder's notion of infrastructure: 'conventions of practice' that require time to develop, an existing 'installed base' referring to past development work, and 'break-down' highlighting repair of ongoing or past work. Yet a first critical insight is that an explicit extension of the notion towards long-term temporal scales is needed, precisely because: "what we understand by the concept of infrastructure has significant consequences in terms of how we design it" (Bowker et al. forthcoming).

\subsection{Temporal orientations: project time and infrastructure time}

The two different temporal orientations in collaborative infrastructure development, 'project time' and 'infrastructure time', are summarized in Table 1. As described in Section 5.4. the tension between short-term and long-term temporal scales is managed within the temporal orientations from their own points of view but not resolved between them. There is a mismatch between developers' project time and information managers' infrastructure time with regard to the duration of a relevant long-term temporal scale. For developers, a project timeframe of approximately three to five years represents long-term, whereas for information managers the long-term relates to an overarching concern for the long-term of ecological science and legacy datasets as well as expectations of data reuse and new technological solutions by future generations. From the point of view of 'infrastructure time', the long-term of three to five years of 'project time' is restricted in comparison to an estimate of 200 years suggested as a relevant 
Table 1. Summary of characteristics of two temporal orientations: project time and infrastructure time.

\begin{tabular}{|c|c|}
\hline Project time & Infrastructure time \\
\hline $\begin{array}{l}\text { Short-term and long-term tension managed } \\
\text { from project time point of view }\end{array}$ & $\begin{array}{l}\text { Short-term and long-term tension managed from } \\
\text { infrastructure time point of view }\end{array}$ \\
\hline $\begin{array}{l}\text { Temporal scale of concern: project length, } \\
\text { long-term approximates } 3-5 \text { years }\end{array}$ & $\begin{array}{l}\text { Temporal scale of concern: infrastructure } \\
\text { lifetime, long-term spans at least multiple } \\
\text { decades }\end{array}$ \\
\hline $\begin{array}{l}\text { The other group's long-term temporal scale } \\
\text { seen as not having an end in sight }\end{array}$ & $\begin{array}{l}\text { The other group's long-term temporal scale seen } \\
\text { as limited and lacking in sustainability }\end{array}$ \\
\hline Temporal orientation closed at project end & orientation favors open-endedness \\
\hline $\begin{array}{l}\text { Forward facing temporal perspective: emphasis } \\
\text { on present-future }\end{array}$ & $\begin{array}{l}\text { Extended temporal perspective: ranges over } \\
\text { past—present—future }\end{array}$ \\
\hline A temporal landscape of discrete periods & A temporal landscape of continuity \\
\hline $\begin{array}{l}\text { Solutions developed as part of a plannable } \\
\text { future within the limits of project timeframes }\end{array}$ & $\begin{array}{l}\text { Infrastructure work unfolds as a series of steps } \\
\text { moving toward an emergent future }\end{array}$ \\
\hline
\end{tabular}

temporal scale for infrastructures (Edwards et al. 2007). However, temporal scales can be expected to be of different duration with different kinds of infrastructures. For instance, temporal scales relevant for information infrastructures based on digital technologies changing at a rapid tempo may be expected to span only some decades. Nonetheless, in the case of the research network information managers, where infrastructure is always considered also in relation to data for which temporal scales can extend over century timeframes, it is safe to say that the long-term temporal scales of infrastructure time extend over multiple decades at minimum.

For the information managers of the research network, 'infrastructure time' involves taking account of the past and present in future plans and actions, defining relationships that include update strategies and enable integration not only at the present time but over time. Thus, the temporal perspective of 'infrastructure time' extends from the present to the future (prospective dimension) and also to the past (retrospective dimension). This is visible in our case study in the ways information managers, after adoption and initial attempts to implement the standard, consider through contextualization how the new metadata standard could be integrated with their installed base with special attention to keeping data secured and balanced with the demands for coordinating and managing units at the research network level. They start their unit dictionary work by accounting for existing or legacy units and embarking on an undertaking at sites to make the metadata standard workable and useful by engaging in a longterm process of modifying and augmenting the unit dictionary, in essence appropriating (Pipek 2005) the metadata standard. While the work takes place 'here and now' and attends to short-term concerns, it also manages continuity over the long-term by accounting both for the demands of the existing legacy 
units and installed base as well as for future repair, foreseeable revision, and anticipated change. Information managers ask what the ramifications of a design decision are not just for the immediate product but for the management of legacy data and not just for an installed base in theory but for their particular installed infrastructure base. They anticipate consequences for future systems and future responsibilities in terms of growth, use, maintenance, modification, migration, and redesign at the site of the current task and of related tasks as well.

'Infrastructure time' of collaborative infrastructure development thus not only addresses the future, satisfies the present, and meets the challenge of linking the two as described in the two-tier approach of Ribes and Finholt (2009) but also ranges over the fuller past-present-future continuum of an 'extended temporal horizon' in a manner similar to that described earlier for data management and curation (Karasti et al. 2006; Karasti and Baker 2008b). In the case of infrastructure time, a process of short-term steps takes the information managers toward an emergent future along an unfolding long-term path of collaborative infrastructure development. This establishes a temporal landscape of continuity where closely associated efforts are planned and aligned as in-situ experience informs present and future plans. This contrasts with the developers' temporal orientation as documented in Table 1 where a temporal landscape of discrete project periods and loosely associated projects are organized as funding opportunities come through.

Project time is prevalent in technology development settings as the tradition of organizing collaborative work through projects is a commonly accepted way for managing software development, information systems design as well as research and development work (Avison and Torkzadeh 2008). Project time as a temporal orientation is closely linked with the notions of project, project management and project-based organization. A project, generally described as "a piece of planned work or an activity which is finished over a period of time and intended to achieve a particular aim" (Cambridge Dictionaries Online, http://dictionary. cambridge.org/). In project management and project-based organizations time is conceived as a key resource that - as a quantifiable and measurable unit - is allocated and actively controlled. Short-term temporal scales of project time are typically tied to temporally bounded, defined tasks to be accomplished while long-term temporal scales are associated with goals to be achieved within the project timeframe.

Recognizing infrastructure time as inclusive of both short-term and long-term temporal scales relevant to the infrastructure point of view is critical. When seen as a tension of short-term efforts versus long-term aims, infrastructure planning does not take into consideration the ongoing negotiation between short-term activities as trajectory-setting for long-term processes. That is, e-infrastructure research can be described as managing the tension of short-term and long-term (Karasti and Baker 2004; Ribes and Finholt 2007) or, alternatively, it can be viewed as a transition to an 'infrastructure time' perspective that involves an 
active mix of ongoing - never-ending - negotiations that create an always reviewed and renewed balance among activities meeting short-term goals while addressing long-term aims and ramifications. In the latter case, the continuing work of simultaneously building and using, maintaining and redesigning the infrastructure is accompanied by an active concern and sensitivity to how the long-term affects activities conducted in the short-term (Lemke 2000). Temporary balances are negotiated through choices made in prioritizing short-term and longterm elements and in changing combinations of short-term and long-term that we call 'infrastructure time'. Infrastructure time, thus, entails a synergistic approach that allows for the continuing processes of negotiation of ever-changing temporary balances resulting from the interplay of multiple temporal scales. To give an example from our case study, the approach to unit dictionary development employed by the information managers simultaneously attends to and creates room for paralleling, sequential and partially overlapping short-term and long-term processes to co-exist. The process for augmenting the network unit dictionary through development of a list of custom units-in-use was identified as a first short-term step with awareness that gaining full engagement of all sites would take longer time but would nevertheless be achievable within a certain, limited timeframe. The mechanisms for submitting and vetting in order to add new units to the network unit registry, on the other hand, were envisioned and planned as continuous, long-term activities given recognition of the inevitable future additions over time.

Evidence of similar synergistic interplay between the temporal orientations of project time and infrastructure time is harder to find in our case study; the profound differences in temporal orientations remain largely perceived as unresolved tensions. Project time based infrastructure development efforts can provide stimuli and impetus for the infrastructure time based development orientation, i.e. continuing design (described in the following subsection) but differing temporal orientations cause problems for participation. This is exemplified in our case by developers with 'project time' orientation funded for short periods of time and information managers with 'infrastructure time' orientation supported to focus on everyday information management responsibilities (Karasti et al. 2006; Karasti and Baker 2008b). With no extra funding or resources, information managers had little chance of committing to project time based infrastructure development. We argue, therefore, that there is an urgent need to develop approaches, methods and tools for collaborative infrastructure development that would allow for and support different temporal orientations to ensure effective and productive collaborations. Furthermore, at another level, this also puts great exigencies on changing e-Research infrastructure development policies, as well as funding opportunities for e-Research infrastructure development. This case suggests the need for supporting both local-level innovation and longer term funding schemes in recognition of the long-term temporal scales involved in scientific information infrastructures (cf. Edwards et al. 2007). 


\subsection{Development orientation: continuing design}

While collaborative work has typically been studied with an interest in spatial distribution, in this study, we document how the collaborative development of a metadata standard is accomplished through temporal distribution of work. The planning by information managers for a network unit registry with a 'scope' category and 'vetting' functionality provides an example of a temporally distributed development process and contrasts with the temporally limited development orientation employed by the metadata standard developers that is more common in systems development organized as projects.

The motivations and aims of the two development orientations differ. In one case, the developers of the metadata standard are motivated by project timing concerns where "the meeting of deadlines is regarded as a high priority, and very often, the highest priority matter" (Button and Sharrock 1996, p. 384), and their aim in collaborative infrastructure development is to provide a successful outcome of the project at hand, i.e. a finished product in the form of a universal standard for a research domain (Millerand and Bowker 2009). In part, this ensures viability for subsequent project funding cycles. Further, the focus is on experimenting and technology transition with lessons learned from previous technologies carried over to subsequent development projects.

In comparison, the aim and motivation of the information managers' collaborative infrastructure development is to secure legacy data and support the conduct of science by providing an ongoing, reliable, and sustainable information environment. Information managers located at research sites become familiar with and sensitive to the challenges involved in balancing both the shortterm temporal scales of seasonal data collection and of information technology work with their own professional understandings of and long-term requirements for information management and growth of information infrastructure. That is, they take a judicious technology approach (Karasti and Baker 2004; Karasti et al. 2006); they are not interested in the technologies as such but in carefully balancing available technologies and demands of data as well as considering optimal timing for changing data related organizational schemas, standards, and/ or technologies.

Both development orientations have their own unique assumptions, development practices and temporal orientations that may well be associated with what Barley (1988) has called a 'temporal subculture'. A temporal subculture refers to an ensemble or community of people that have established joint rhythms important for their collaborative activity and may share commitment over time to an overarching goal (Barley 1988). In contrast to the development orientation that has evolved largely with new computer science technologies and a focus on projects, we suggest 'continuing design' that incorporates the multiple temporal scales associated with information infrastructure development. The two infrastructure development orientations are summarized in Table 2. 
Continuing design accounts for the continuity of functionality of the infrastructure, to ensure that a working system is in place all the time. A preferred judicious technology approach, rather than radical change, enables (re) design while minimizing disturbance of ongoing practices. In continuing design it is also possible to take into account the existing data and infrastructure, i.e. the 'installed base'. In other words, radical change is viewed as likely to compromise 'working' infrastructure or to put legacy data in peril unlike incremental change associated with an iterative approach (e.g. Fischer and Ostwald 2002). Thus rather than discarding the existing standard unit dictionary, a parallel effort was undertaken with development of a complementary network unit dictionary strategy. This strategy drew upon the basic unit dictionary structure made available in the metadata standard, recognized the existence of the 'standard' category for units, and elaborated upon the 'custom' category by adding a mechanism and process for gathering together the existing units at sites and creating a network unit registry with a vetting feature that supports inclusion of new units and movement of units from a local site scope to a network scope. This finely tuned, sociotechnical in-practice innovation integrates the idea of inclusion of all sites within the network. It also gives an example of the differences between the development orientations in how collaborative work is coordinated. For this type of temporally open-ended activity, there is hardly time in a project time development orientation where the priority is to innovate with new technologies in response to the needs of larger audiences by taking account of domain similarities and where the question of how long tasks will take is consequential (Avison and Torkzadeh 2008).

Table 2. Summary of characteristics of two infrastructure development orientations: project time and infrastructure time.

Project time development orientation

Focus on new technology and development of experimental solutions

Focus on universal mechanisms for data organization

Responsibility to transition to new and better technology solutions

Finished products as solutions

Success perceived as declaration of a universal standard at project end

Development in mind

Innovation in technology development to be deployed in the research domain at large

Response to domain requirements and to needs of a general public

Insight into potential tools for the future
Infrastructure time development orientation

Judicious approach to technology and development of sustainable solutions

Focus on local data and contextualized mechanisms for data organization

Responsibility to secure continuity of the data through time and to support ongoing science

Continuity of partial compilations

Success perceived as a contextualized, appropriated and enacted metadata standard Development, maintenance and redesign in mind Innovation in sociotechnical development carried out in practice with network wide inclusion

Response to site and research network requirements

Insight into local relevance of tools and semantic work for ongoing infrastructure development 
In effect, we are expanding the concept of 'continuing design in use' (Henderson and Kyng 1991) to 'continuing design' in order to broaden the focus on 'use' to the long-term perspective required for sustainable collaborative infrastructure development that blurs the boundaries of use, design, implementation, maintenance, and redesign (Karasti and Baker 2004; Karasti et al. 2006). Continuing design is a development orientation where the relation between shortterm and long-term - traditionally seen as a tension - is addressed and accounted for from the point of view of infrastructure time by incorporating it as a foundational design consideration.

\section{Conclusions}

With this study of semantic work and tools development associated with standard-making as a collaborative infrastructure development, we demonstrate that investigating the temporal aspects of collaboration is equally as important as the more recognized spatial aspects. Given the experience gained with short-term temporal aspects in $\mathrm{CSCW}$, it is now time to augment such studies by investigation of issues relating to long-term temporalities. This includes exploring time as a contributor to diversity and represents an alternative to focus on the temporal extremes as a short-term and long-term polemic tension. We believe that the concepts developed in this paper, i.e. the temporal orientation of 'infrastructure time' and the design orientation of 'continuing design', can be useful in settings of long-term collaborative infrastructure development and invite researchers to examine them critically.

The ramifications of the notion of 'infrastructure time' are many. It does not promise solutions to recognized CSCW problematics, rather it proposes challenges for temporal diversification and motivation for more temporally oriented work to be carried out in the CSCW field. Key CSCW concepts will benefit from reexamination in light of extended temporal scales, and new ones explicitly encompassing the long-term will have to be constructed. Serious interest in the temporal dimension of collaboration requires extending the existing research methodological repertoire, such as with long-term involvement. Although we have not been focusing on collaborative technologies in this paper, we suggest in studies of collaboration that an increased interest in temporalities in general, and long-term in particular, would also have an effect on the technologies developed.

We find in large-scale research an understanding is emerging that infrastructure development is an interdisciplinary activity involving domain scientists, technology developers and data specialists. As demonstrated in this paper, participants in collaborative infrastructure development will also have to account for and accommodate long-term temporal scales and orientations, thus methods and tools need to be developed to support them. Further, funding agency managers will need to understand the long-term temporal scales pertinent to infrastructure development. Funding not just for short-term, cutting-edge 
technology projects but also for innovation that emerges within long-term, continuing design projects is critically important. Long-term funding makes it financially and organizationally possible for the development orientations of both project time and infrastructure time to co-exist, putting them in a position to coinform and cross-fertilize.

Known for its insights into collaborative work gained largely through microanalytic workplace studies, CSCW research holds the potential to contribute in important ways to the study and development of infrastructure including e-Research infrastructure. Due to the traditional bias toward short-term, we have, in this paper, emphatically foreground the long-term temporal scale and perspective because both short-term and long-term temporal orientations and development approaches have to be understood in relation to each other in order to support large-scale and longlasting infrastructures. We encourage future $\mathrm{CSCW}$ research to encompass an interest in more diversified temporalities so that forthcoming studies of infrastructure are better prepared to address and integrate extended temporal scopes in to their explorations of further issues of collaborative infrastructure development. There is currently little empirically-based understanding about how e-Research infrastructures are integrated into actual research practices and collaborative endeavors, and how they are taken up, enacted, tailored, appropriated and further developed over time. Our collective long-term investigation has just begun.

\section{Acknowledgements}

Support is provided by Academy of Finland Research Fellowships \#119814, \#125467 and \#130260, NSF SBE/SES \#04-33369, OCE \#04-05069 CCE, OPP \#08-23101 PAL, CalCOFI, and Social Sciences and Humanities Research Council of Canada Postdoctoral Fellowship \#756-2003-0099.

Open Access This article is distributed under the terms of the Creative Commons Attribution Noncommercial License which permits any noncommercial use, distribution, and reproduction in any medium, provided the original author(s) and source are credited.

\section{Notes}

1. We are aware of the notions having differences, e.g. geographical usage and disciplinary coverage, but for our purposes in this paper the similarities between the emerging notions are more important, and therefore we use the terms interchangeably.

2. In comparison, it is interesting to note a field often taken as a subfield of e-Science in which long-term perspective is of explicit concern. The field of digital preservation and curation deals with the organization and management of digital research data and records over time (National Science Board 2005; Lord and Macdonald 2003).

3. The term 'project' here refers to a research entity; later on in the paper we discuss development projects as a distinct notion.

4. We want to thank one of the reviewers for clearly pointing this out. 


\section{References}

Abbate, J. (1999). Inventing the internet. Cambridge: MIT.

Adam, B. (1990). Time and social theory. Cambridge: Polity.

Adam, B. (1994). Perceptions of time. In T. Ingold (Ed.), Companion encyclopedia of anthropology: Humanity, culture, and social life (pp. 503-526). London: Routledge.

Ancona, D., Goodman, P. S., Lawrence, B. S., \& Tushman, M. L. (2001). Time: a new research lens. The Academy of Management Review, 26(4), 645-663.

ARL Workshop in New Collaborative Relationships (2006). To stand the test of time: long-term stewardship of digital data sets in science and engineering. A Report to the National Science Foundation from the ARL Workshop on New Collaborative Relationships: The Role of Academic Libraries in the Digital Data Universe. Arlington, VA. Available: http:/www.arl.org/ bm doc/arlbr249datasteward.pdf. [Last referenced: 11.10.2009].

Aronova, E., Baker, K. S., \& Oreskes, N. (2010). Big science and big data in biology: from the International Geophysical Year through the International Biological Program to the Long-Term Ecological Research, 1957-present. Historical Studies in the Natural Sciences, 40(2), 183-224.

Arzberger, P., Schroeder, P., Beaulieu, A., Bowker, G. C., Casey, K., Laaksonen, L., et al. (2004). Promoting access to public research data for scientific, economic, and social development. Data Science Journal, 3, 135-152.

Atkins, D. E., Droegemeier, K. K., Feldman, S. I., Garcia-Molina, H., Klein, M. L., Messerschmitt, D. G., et al. (2003). Revolutionizing science and engineering through cyberinfrastructure, Report of the National Science Foundation Blue-Ribbon Advisory Panel on Cyberinfrastructure. Available: http://www.communitytechnology.org/nsf_ci_report/. [Last referenced: 11.10.2009].

Avison, D. E., \& Torkzadeh, G. (2008). Information systems project management. Thousand Oaks: SAGE Publications.

Baker, K. S., \& Chandler, C. (2008). Enabling long-term oceanographic research: Changing data practices, information management strategies and informatics. Deep Sea Research II, 55, 2132 2142.

Baker, K. S., \& Millerand, F. (2008). Scientific information infrastructure design: information environments and knowledge provinces. Proceedings of the American Society for Information Science and Technology, 44(1), 1-9.

Baker, K., \& Millerand, F. (forthcoming). Infrastructuring ecology: Challenges in achieving data sharing. In J. Parker, N. Vermeulen, \& B. Penders (Eds.), Collaboration in the New Life Sciences. Ashgate. (To be published in 2010).

Baker, K. S., Benson, B. J., Henshaw, D. L., Blodgett, D., Porter, J. H., \& Stafford, S. G. (2000). Evolution of a multisite network information system: the LTER information management paradigm. BioScience, 50(11), 963-978.

Baker, K. S., Ribes, D., Millerand, F., \& Bowker, G. C. (2005). Interoperability strategies for scientific cyberinfrastructure: Research and practice. Proceedings of the American Society for Information Systems and Technology Conference. Charlotte, NC, USA, October 28-November 2005, p. 3.

Baker, K. S., Pennington, D., \& Porter, J. H. (2006a). Multiple approaches to semantic issues: vocabularies, dictionaries and ontologies. LTER DataBits Newsletter, Spring 2006. Available: http://intranet.lternet.edu/archives/documents/Newsletters/DataBits/06spring/\#03fa. [Last referenced: 11.10.2009].

Baker, K., Yarmey, L., Haber, S., Millerand, F., \& Servilla M. (2006b). Creating information infrastructure through community dictionary processes. LTER DataBits Newsletter, Spring 2006. Available: http://intranet.lternet.edu/archives/documents/Newsletters/DataBits/06spring/\#5fa. [Last referenced: 11.10.2009].

Bardram, J. E. (2000). Temporal coordination. Computer Supported Cooperative Work (CSCW). An International Journal, 9, 157-187. 
Barley, S. R. (1988). On technology, time, and social order: Technically induced change in the temporal organization of radiological work. In F. A. Dubinskas (Ed.), Making time: Ethnographies of high-technology organizations (pp. 123-169). Philadelphia: Temple University.

Baskerville, R., Ramesh, B., Levine, L., Pries-Heje, J., \& Slaughter, S. (2003). Is internet-speed software development different? IEEE Software, 20(6), 70-77.

Borgman, C. L. (2007). Scholarship in the digital age: Information, infrastructure and the internet. Cambridge: MIT.

Borgman, C. L., Wallis, J. C., Mayernik, M. S., \& Pepe, A. (2007). Drowning in data: Digital library architecture to support scientific use of embedded sensor networks. In Proceedings of the ACM/IEEE Joint Conference on Digital Libraries 2007, Vancouver, BC.

Bos, N., Zimmerman, A. S., Olson, J. S., Yew, J., Yerkie, J., Dahl, E., et al. (2008). From shared databases to communities of practice: A taxonomy of collaboratories. In G. M. Olson, A. S. Zimmerman, \& N. Bos (Eds.), Scientific collaboration on the internet (pp. 53-72). Cambridge: MIT.

Bowker, G. C. (1994). Information mythology and infrastructure. In L. Bud-Frierman (Ed.), Information Acumen: The understanding and use of knowledge in modern business (pp. 231-247). London: Routledge.

Bowker, G. C. (2000). Biodiversity datadiversity. Social Studies of Science, 30(5), 643-683.

Bowker, G. C., Baker, K. S., Millerand, F., \& Ribes, D. (forthcoming). Towards information infrastructure studies: Ways of knowing in a networked environment. In J. Hunsinger, M. Allen, \& L. Klasrup (Eds.), International Handbook of Internet Research. Springer. (To be published in 2010).

Brand, S. (1999). The clock of the long now: Time and responsibility. New York: Basic Books.

Brunt, J. (1998). The LTER network information system: A framework for ecological information management. In C. Aguirre-Bravo \& C. R. Franco (Eds.), North American Science Symposium: Toward a Unities Framework for Inventorying and Monitoring Forest Ecosystem Resources. Guadalajara, Mexico, November 2-6, 1998, pp. 435-440.

Bucciarelli, L. L. (1988). Engineering design process. In F. A. Dubinskas (Ed.), Making time. Ethnographies of high-technology organizations (pp. 92-122). Philadelphia: Temple University Press.

Button, G., \& Sharrock, W. (1996). Project work: the organisation of collaborative design and development in software engineering. Computer Supported Cooperative Work (CSCW). An International Journal, 5, 369-386.

Callahan, J. T. (1984). Long-term ecological research. BioScience, 34(6), 363-367.

Castells, M. (1996). The information age: Economy, society and culture. Oxford: Blackwell Publishers.

Crabtree, A., Hemmings, T., Rodden, T., \& Mariani, J. (2003). Informing the development of calendar systems for domestic use. In the Proceedings of the Eighth European Conference on Computer Supported Cooperative Work (ECSCW'03), Helsinki, Finland, September 14-18, 2003, pp. 119-138.

Cronon, W. (1991). Nature's Metropolis: Chicago and the Great West. New York: W.W. Norton.

Cushing, J. B., Vanderbilt, K., Brunt, J.W., Gupta, A., Jones, M. B., \& McCartney, P. (2005). NSF Long Term Ecological Research Sites Praxis et Theoria-LTER Information Management and CS Research. Proceedings of the 17th international conference of scientific and statistical database management (SSDBM 2005), Santa Barbara, CA, USA, June 27-29, 2005, pp. 303306.

Dittrich, Y., Eriksén, S., \& Wessel, B. (2009). From knowledge transfer to situated innovation: Cultivating spaces for co-operation in innovation and design between academics, user-groups and ICT provides. Research report. Blekinge Institute of Technology, Sweden. Available: http:// 
www.bth.se/fou/forskinfo.nsf/all/.../innovation-technrep-final_rev.pdf. [Last referenced: 11.10.2009].

Dix, A., Ramduny, D., \& Wilkinson, J. (1998). Interaction in the large. Interacting with Computers, 11, 9-32.

Dubinskas, F. A. (1988). Janus organizations: Scientists and managers in genetic engineering firms. In F. A. Dubinskas (Ed.), Making time: Ethnographies of high-technology organizations (pp. 170-232). Philadelphia: Temple University.

Edwards, P. N., Jackson, S. J., Bowker, G. C., \& Knobel, C. P. (2007). Understanding infrastructure: Dynamics, tensions, and design. Final report of the workshop History and Theory of Infrastructure: Lessons for New Scientific Cyberinfrastructures. NSF, Office of Cyberinfrastructure. p. 50. Available: http://www.si.umich.edu/InfrastructureWorkshop/documents/Under standingInfrastructure2007.pdf. [Last referenced: 11.10.2009].

Edwards, P. N., Bowker, G. C., Jackson, S. J., \& Williams, R. (2009). Introduction: an agenda for infrastructure studies. Journal of the Association for Information Systems, 10(5), 364-374.

Egger, E., \& Wagner, I. (1993). Negotiating temporal orders: the case of collaborative time management in a surgery clinic. Computer Supported Cooperative Work (CSCW). An International Journal, 1, 255-275.

Fergraus, E. H., Andelman, S., Jones, M. B., \& Schildhauer, M. (2005). Maximizing the value of ecological data with structured metadata: an introduction to Ecological Metadata Language (EML) and principles for metadata creation. Bulletin of the Ecological Society of America, 86, $158-168$.

Finholt, T. (2002). Collaboratories. In E. B. Cronin (Ed.), Annual review of information science and technology, vol. 36 (pp. 73-107).

Fischer, G., \& Ostwald, J. (2002). Seeding, evolutionary growth, and reseeding: Enriching participatory design with informed participation. In Proceedings of Participatory Design Conference (PDC'02), Malmö, Sweden, June 23-25, 2002. Palo Alto: CPSR, pp. 135-143.

Foster, D. R., \& Aber, J. (2004). Forests in time: the Environmental consequences of 1000 years of change. New England: Yale University Press.

Freeman, P. A. (2007). Is 'designing' cyberinfrastructure —or, even, defining it—possible? First Monday, vol. 12, no. 6. Available: http://firstmonday.org/issues/issue12_6/freeman/index.html. [Last referenced: 11.10.2009].

Hanseth, O., \& Lundberg, N. (2001). Designing work oriented infrastructures. Computer Supported Cooperative Work (CSCW). An International Journal, 10(3-4), 347-372.

Hanseth, O., Monteiro, E., \& Hatling, M. (1996). Developing information infrastructure: the tension between standardization and flexibility. Science, Technology and Human Values, 21(4), 407-426.

Harmon, M. E., Nadelhoffer, K. J., \& Blair, J. M. (1999). Measuring decomposition, nutrient turnover, and stores in plant litter. In G. P. Robertson, C. S. Bledsoe, D. C. Coleman, \& P. Sollins (Eds.), Standard soil methods for long term ecological research (pp. 202-240). New York: Oxford University Press.

Hedstrom, M. (2003). It's about time: research challenges in digital archiving and long-term preservation, Final Report on Workshop on Research Challenges in Digital Archiving and Longterm Preservation, April 12-13, 2002, National Science Foundation and The Library of Congress. Available: http://www.si.umich.edu/digarch/NSF\%200915031.pdf. [Last referenced: 11.10.2009].

Henderson, A., \& Kyng, M. (1991). There's no place like home: Continuing design in use. In J. Greenbaum \& M. Kyng (Eds.), Design at work. London: Lawrence Erlbaum.

Hey, T., \& Trefethen, A. E. (2003). The data deluge: An e-Science perspective. In F. Berman, G. Fox, \& T. Hey (Eds.), Grid computing: Making the global infrastructure a reality (pp. 809-824). Hoboken: Wiley. 
Hine, C. (2008). Systematics as cyberscience: Computers, change, and continuity in science. Boston: MIT.

Hobbie, J. E., Carpenter, S. R., Grimm, N. B., Gosz, J. R., \& Seastedt, T. R. (2003). The US long term ecological research program. BioScience, 53(1), 21-32.

Hughes, T. P. (1983). Networks of power: Electrification in Western Society, 1880-1930. Baltimore: Johns Hopkins University Press.

Jacobs, K. (2006). Advanced topics in information technology standards and standardization research. Hershey: Idea Group Publishing.

Jirotka, M., Procter, R., Hartswood, M., Slack, R., Simpson, A., Coopmans, C., et al. (2005). Collaboration and trust in healthcare innovation: the eDiaMoND Case Study. Computer Supported Cooperative Work (CSCW). An International Journal, 14(4), 369-398.

Jirotka, M., Procter, R., Rodden, T., \& Bowker, G. C. (2006). Special issue: collaboration in eResearch. Computer Supported Cooperative Work (CSCW). An International Journal, 15(4), 251-255.

Johansen, R. (1988). Groupware. Computer support for business teams. New York: Free.

Jones, M. B., Berkley, C., Bojilova, J., \& Schildhauer, M. (2001). Managing scientific metadata. IEEE Internet Computing, 5(5), 59-68.

Kaplan, S., \& Seebeck, L. (2001). Harnessing complexity in CSCW. In Proceedings of the Seventh European Conference on Computer Supported Cooperative Work (ECSCW01). Bonn, Germany, September 16-20, 2001, pp. 359-378.

Karasti, H., \& Baker, K. (2004). Infrastructuring for the long-term: Ecological information management. Hawaii International Conference on System Sciences 2004 (HICSS'37). Hawaii, USA, January 5-8, 2004, p. 10.

Karasti, H., \& Baker, K. S. (2008a). Community design: Growing one's own information infrastructure. In Proceedings of Participatory Design Conference (PDC'08), Bloomington, IN, USA, October 1-4, 2008. Computer Professionals for Social Responsibility (CPSR).

Karasti, H., \& Baker, K. S. (2008b). Digital data practices and the long term ecological research program growing global. International Journal of Digital Curation, 3(2), 42-58.

Karasti, H., \& Syrjänen, A.-L. (2004). Artful infrastructuring in two cases of community PD. In Proceedings of Participatory Design Conference 2004 (PDC'04) Artful Integration: Interweaving Media, Materials and Practices. Toronto, Canada, July 27-31, 2004. ACM Press, pp. $20-30$.

Karasti, H., Baker, K. S., \& Halkola, E. (2006). Enriching the notion of data curation in e-Science: data Managing and Information Infrastructuring in the Long Term Ecological Research (LTER) Network. Computer Supported Cooperative Work (CSCW). An International Journal, 15(4), 321-358.

Klein, J. T. (1990). Interdisciplinarity: History, theory, and practice. Detroit: Wayne State University Press.

Latour, B. (1996). Aramis or the love of technology. Cambridge: Harvard University Press.

Lave, J., \& Wenger, E. (1991). Situated learning: Legitimate peripheral participation. Cambridge: Cambridge University Press.

Lawrence, K. A. (2006). Walking the Tightrope: the balancing acts of large e-Research project. Computer Supported Cooperative Work (CSCW). An International Journal, 15(4), 385-411.

Lee, H. (2003). Your time and my time: a temporal approach to groupware calendar systems. Information \& Management, 40(3), 159-164.

Lee, C. P., Dourish, P., \& Mark, G. (2006). The human infrastructure of cyberinfrastructure. Proceedings of the Computer Supported Cooperative Work (CSCW'06). Banff, Alberta, Canada, November 4-8, 2006. ACM, pp. 483-492.

Lemke, J. L. (2000). Across the scales of time: artifacts, activities, and meanings in ecosocial systems. Mind, Culture, and Activity, 7(4), 273-290. 
Lindstaedt, S. N., \& Schneider, K. (1997). Bridging the gap between face-to-face communication and long-term collaboration. In Proceedings of GROUP'97. Phoenix, Arizona, United States, November 16-19, 1997. ACM, pp. 331-340.

Lord, P., \& Macdonald, A. (2003). e-Science curation report-data curation for e-Science in the UK: An audit to establish requirements for future curation and provision. Twickenham, UK: The Digital Archiving Consultancy Limited. Available: http://www.jisc.ac.uk/uploaded_documents/eScienceReportFinal.pdf. [Last referenced: 11.10.2009].

Lougher, R., \& Rodden, T. (1993). Supporting long-term collaboration in software maintenance. In Proceedings of the Conference on Organizational Computing Systems (COOCS'93). Milpitas, CA, USA, November, 1-4, 1993. ACM, pp. 228-238.

Lyytinen, K., \& King, J. L. (2006). Standard making: a critical research frontier for information systems research. MIS Quarterly, 30, 405-411.

Magnuson, J. J. (1990). Long-term ecological research and the invisible present. BioScience, 40(7), 495-501.

McCartney, P., \& Jones, M. B. (2002). Using XML-encoded metadata as a basis for advanced information systems for ecological research. Proceedings of the 6th World Multiconference Systemics, Cybernetics and Informatics. Orlando, Florida, USA, July 14-18, 2002. pp. 379-384.

Michener, W. K. (2000). Metadata. In W. K. Michener \& J. W. Brunt (Eds.), Ecological dataDesign, management and processing (pp. 92-116). Oxford: Blackwell Science Ltd.

Michener, W., Brunt, J., Helly, J., Kirchner, T., \& Stafford, S. G. (1997). Nongeospatial metadata for the ecological sciences. Ecological Applications, 7, 330-342.

Millerand, F., \& Baker, K. S. (2010). Who are the users? From a single user to a web of users in the design of a working standard. Information Systems Journal, 20, 137-161.

Millerand, F., \& Bowker, G. C. (2008). Metadata, trajectoires et «enaction». In C. Rosental (Ed.), La cognition au prisme des sciences sociales (pp. 277-303). Paris: Editions des Archives Contemporaines.

Millerand, F., \& Bowker, G. C. (2009). Metadata standard: Trajectories and enactment in the life of an ontology. In M. Lampland \& S. L. Star (Eds.), Standards and their stories. How quantifying, classifying, and formalizing practices shape everyday life (pp. 149-165). Ithaca: Cornell University Press.

Millerand, F., Baker, K. S., Benson, B., \& Jones, M. (2005). Lessons learned from EML about the community process of standard implementation. LTER DataBits Newsletter (Fall): http://intranet. lternet.edu/archives/documents/Newsletters/DataBits/05fall/\#4fa. [Last referenced: 11.10.2009].

Monteiro, E. (1998). Scaling information infrastructure: the case of next-generation IP in the internet. The Information Society, 14, 229-245.

Nandhakumar, J. (2002). Managing time in a software factory: temporal and spatial organization of IS development activities. The Information Society, 18, 251-262.

Nandhakumar, J., \& Jones, M. (2001). Accounting for time: managing time in project-based teamworking. Accounting, Organizations and Society, 26, 193-214.

National Research Council. (2007). Environmental Data Management at NOAA: Archiving, stewardship, and access. Washington: National Academies Press.

National Science Board (2005). Long lived digital data collections: Enabling research and education in the 21st Century, National Science Board (NSB-05-40). Available: http://www.nsf.gov/pubs/ 2005/nsb0540/. [Last referenced: 11.10.2009].

National Science Foundation (2007). National Science Foundation, Cyberinfrastructure Vision for 21st Century Discovery, National Science Foundation, Arlington VA (March 2007). Available: http://www.nsf.gov/pubs/2007/nsf0728/nsf0728.pdf. [Last referenced: 11.10.2009].

Nilsson, M., \& Hertzum, M. (2005). Negotiated rhythms of mobile work: time, place, and work schedules. In Proceedings of GROUP'05. Sanibel Island, FL, USA, November 6-9, 2005. ACM, pp. 148-157. 
Olson, G. M., \& Olson, J. (2000). Distance matters. Human Computer Interaction, 15, 139-179.

Olson, G. M., Zimmerman, A., \& Bos, N. (2008). Scientific collaboration on the internet. Cambridge: MIT.

Orlikowski, W. J., \& Yates, J. (2002). It's about time: temporal structuring in organizations. Organization Science, 13(6), 684-700.

Pipek, V. (2005). From tailoring to appropriation support: Negotiating groupware usage. $\mathrm{PhD}$ Dissertation. Department of Information Processing Science. University of Oulu, Finland.

Pipek, V., \& Wulf, V. (2009). Infrastructuring: towards an integrated perspective on the design and use of information technology. Journal of the Association for Information Systems, 10(5), 447473.

Randall, D., Sharrock, W., Rooksby, J., Lin, Y., \& Procter, R. (2007). Ontology building as practical work: Lessons from CSCW. 3rd e-Social Science conference, Ann Arbor, Michigan, USA, October 7-9, 2007. Available: http://ess.si.umich.edu/papers/paper178.pdf. [Last referenced: 11.10.2009].

Randall, D., Stevens, R., Sharrock, W., Procter, R., Lin, Y., \& Poschen, M. (2009). What about sea urchins? Collaborative Ontology Building among Bio-Informaticians. The 5th International Conference on e-Social Science. Cologne, Germany, June 24-26, 2009. pp. 10.

Reddy, M., \& Dourish, P. (2002). Finger on the pulse: Temporal rhythms and information seeking in medical care. Proceedings of Computer Supported Cooperative Work (CSCW'02). New Orleans, LA, USA, November 16-20, 2002 (pp. 344-353). New York: ACM.

Reddy, M. C., Dourish, P., \& Pratt, W. (2006). Temporality in medical work: time also matters. Computer Supported Cooperative Work (CSCW). An International Journal, 15, 29-53.

Ribes, D., \& Bowker, G. C. (2008). Organizing for multidisciplinary collaboration: The case of GEON. In G. M. Olson, J. S. Olson, \& A. Zimmerman (Eds.), Scientific collaboration on the internet (pp. 311-330). Cambridge: MIT.

Ribes, D., \& Finholt, T. (2007). Tensions across the scales: Planning infrastructure for the longterm. GROUP'07, Sanibel Island, Florida, USA, November 4-7, 2007. ACM.

Ribes, D., \& Finholt, T. (2009). The long now of technology infrastructure: articulating tensions in development. Journal of the Association for Information Systems, 10(5), 375-398.

Ribes, D., Baker, K. S., Millerand, F., \& Bowker, G. C. (2005). Comparative interoperability project: configurations of community, technology, and organization. Proceedings of the Second ACM/IEEE-CS Joint Conference on Digital Libraries (pp. 65-66). New York: ACM.

Rolland, K. H., \& Monteiro, E. (2002). Balancing the local and the global in infrastructural information systems. The Information Society, 18, 87-100.

Sandusky, R. J. (2003). Infrastructure management as cooperative work: implications for systems design. Computer Supported Cooperative Work (CSCW). An International Journal, 12, 97-122.

Schmidt, K., \& Rodden, T. (1996). Putting it all together: Requirements for a CSCW platform. In D. Shapiro, M. Tauber, \& R. Traunmüller (Eds.), The design of computer-supported cooperative work and groupware systems (pp. 157-176). Amsterdam: North-Holland Elsevier.

Schuurman, N., \& Balka, E. (2008). alt.metadata.health: ontological context for data use and integration. Computer Supported Cooperative Work (CSCW). An International Journal, 18, 83108.

Seebeck, L., Kim, R. M., \& Kaplan, S. (2005). Emergent temporal behaviour and collaborative work. The Ninth European Conference on Computer-Supported Cooperative Work. Paris, France, September 18-22, 2005. Springer, pp. 123-142.

Smith, R. C. (2003). Century to Millennial Timescale - Introductory overview in climate variability and ecosystem response at LTER sites. In D. Greenland, D. G. Goodin, \& R. C. Smith (Eds.), Climate variability and ecosystem response at long-term ecological research sites (pp. 317-318). New York: Oxford University Press. 
Sonnenwald, D. H. (2003). Expectations for a scientific collaboratory: A case study. In Proceedings of GROUP'03. Sanibel Island, Florida, USA, November 9-12, 2003. ACM Press, pp. 68-74.

Spencer, B., Butler, R., Ricker, K., Marcusiu, D., Finholt, T., Foster, I. et al. (2006). Cyberenvironment project management: Lessons learned. Available: http://neesgrid.ncsa.uiuc. edu/documents/CPMLL.pdf. [Last referenced: 11.10.2009].

Stacey, P., \& Nandhakumar, J. (2009). A temporal perspective of the computer game development process. Information Systems Journal, 19(5), 479-497.

Star, S. L. (1999). The ethnography of infrastructure. American Behavioral Scientist, 43(3), 377 391.

Star, S. L. (2002). Infrastructure and ethnographic practice: working on the fringes. Scandinavian Journal of Information Systems, 14(2), 107-122.

Star, S. L., \& Bowker, G. C. (2002). How to infrastructure? In L. A. Lievrouw \& S. L. Livingstone (Eds.), The handbook of new media. Social shaping and consequences of ICTs (pp. 151-162). London: Sage Publications.

Star, S. L., \& Lampland, M. (2009). Standards and their stories: How quantifying, classifying, and formalizing practices shape everyday life. Ithaca: Cornell University Press.

Star, S. L., \& Ruhleder, K. (1996). Steps toward an ecology of infrastructure: borderlands of design and access for large information spaces. Information Systems Research, 7(1), 111-134.

Strauss, A., Fagerhaugh, S., Suczek, B., \& Wiener, C. (1985). Social organization of medical work. Chicago: University of Chicago Press.

Traweek, S. (1988). Beamtimes and lifetimes: The world of high energy physicists. Cambridge: Harvard University Press.

Trigg, R. H., \& Bødker, S. (1994). From implementation to design: Tailoring and the emergence of systemization in CSCW. Proceedings of the CSCW '94. Chapel Hill, NC, USA, October 22-26, 1994 (pp. 45-54). New York: ACM.

Turner, W., Bowker, G. C., Gasser, L., \& Zacklad, M. (2006). Information infrastructures for distributed collective practices. Computer Supported Cooperative Work (CSCW). An International Journal, 15, 93-110.

Tyler, J. R., \& Tang, H. J. (2003): When can i expect an email response? A study of rhythms in email usage. In Proceedings of the Eighth European Conference on Computer Supported Cooperative Work (ECSCW'03), Helsinki, Finland, September 14-18, 2003. Norwell: Kluwer Academic Publishers, pp. 239-258.

Vann, K., \& Bowker, G. C. (2006). Interest in production: On the configuration of technologybearing labours for epistemic IT. In C. Hine (Ed.), New infrastructures for knowledge production: Understanding science (pp. 71-97). Hershey: Information Science Publishing.

Wulf, W. A. (1993). The collaboratory opportunity. Science, 261(5123), 854-855.

Zaheer, S., Albert, S., \& Zaheer, A. (1999). Time scales and organizational theory. The Academy of Management Review, 24(4), 725-741.

Zerubavel, E. (1977). The French Republican Calendar: a case study in the sociology of time. American Sociological Review, 42(6), 868-877.

Zimmerman, A. S. (2003). Data sharing and secondary use of scientific data: experiences of ecologists. PhD dissertation, Information and Library Studies, University of Michigan, USA.

Zimmerman, A. S. (2007). A socio-technical framework for cyberinfrastructure design. In Proceedings of e-Social Science. Ann Arbor, MI, USA, October 7-9 2007, p. 10. 